\title{
Investigation of the process of abrasive waterjet cutting of steels based on numerical simulation
}

\author{
Anton Kurnenkov ${ }^{1, *}$, Alexei Shurigin ${ }^{1}$, and Vladimir Glebov ${ }^{1}$ \\ ${ }^{1}$ Arzamas Politechnical Institute the branch of Nizhniy Novgorod State Technical University named \\ after R.E. Alekseev, Arzamas 607227, Russia
}

\begin{abstract}
The paper presents the results of 3D modeling the process of abrasive waterjet cutting of structural carbon and stainless steel workpiece. The Johnson-Cook model is selected as a material model. Distributions of stress fields in the cutting zone are obtained, as well as the dependences of depth of cut on jet traverse rate at jet velocities of $400 \ldots 700 \mathrm{~m} / \mathrm{s}$ and dependences of cutting force on jet velocity at jet traverse rates of $100 \ldots$ $400 \mathrm{~mm} / \mathrm{min}$.
\end{abstract}

The process of abrasive waterjet cutting is relevant due to its advantages:

- versatility, the abrasive waterjet easily cuts almost any materials, while there are no structural violations and changes in the physical and mechanical characteristics of the processed material;

- lack of thermal effects on the workpiece and changes in its physico-chemical properties, since the temperature in the cutting zone does not exceed $93^{\circ} \mathrm{C}$;

- cutting contour can have any curvature and complexity;

- environmental friendliness, fire and explosion safety.

Debugging of technological parameters of abrasive waterjet machining of various materials during experimental studies is in many cases a difficult task; therefore, the use of numerical modeling of the process of abrasive waterjet cutting in order to establish rational operating parameters is relevant [1-4].

In the article, the problem of modeling of abrasive waterjet cutting of structural carbon (AISI 1010) and stainless (AISI 321) steels was considered. A rectangular parallelepiped with the following dimensions is adopted as a workpiece: length - $40 \mathrm{~mm}$, height - $20 \mathrm{~mm}$ and width $-20 \mathrm{~mm}$. A liquid jet with a diameter of $1 \mathrm{~mm}$ containing abrasive particles is modeled by the SPH method [5]. The jet velocity varies from $400 \mathrm{~m} / \mathrm{s}$ to $700 \mathrm{~m} / \mathrm{s}$, and the traverserate - from $100 \mathrm{~mm} / \mathrm{min}$ to $400 \mathrm{~mm} / \mathrm{min}$. Garnet sand with a grain size of 150 200 microns is used as an abrasive. The mass flow rate of the abrasive grains is assumed to be $7.5 \mathrm{~g} / \mathrm{s}$.

The schematic for model is shown in Fig. 1, a three-dimensional model for numerical simulation is presented in Fig. 2.The model consists of 300,000 finite elements.

\footnotetext{
* Corresponding author: asm061@list.ru
} 


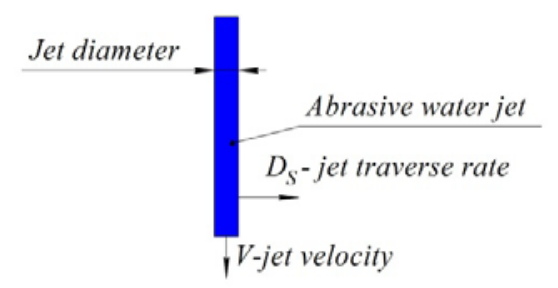

Workpiece



Fig. 1. Schematic for model

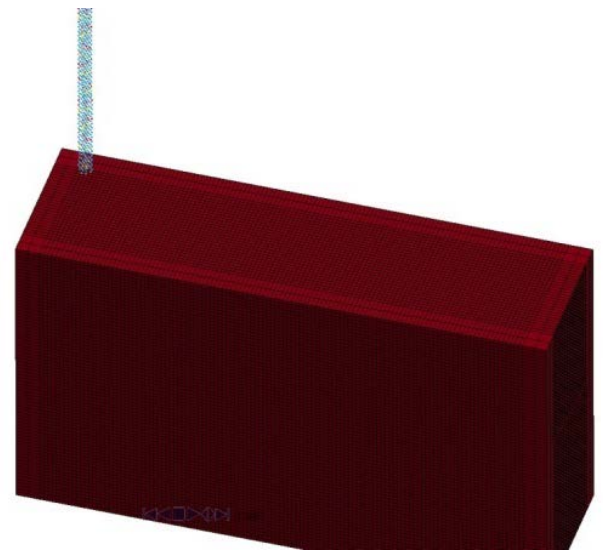

Fig. 2. 3D model

In numerical modeling, one of the main steps is the selection of a suitable material model. A Johnson-Cook material model is selected as the workpiece material model, which allows to take into account such aspects as plastic deformations, stresses, fracture criterion and can accurately describe the selected material. The constants for the materials are presented in Table 1.

Table 1.Johnson-Cook constants for AISI 1010 and AISI 321

\begin{tabular}{|c|c|c|c|c|c|c|c|c|c|c|}
\hline & $\begin{array}{c}\mathrm{A} \\
(\mathrm{MPa})\end{array}$ & $\begin{array}{c}\mathrm{B} \\
(\mathrm{MPa})\end{array}$ & $\mathrm{n}$ & $\mathrm{C}$ & $\mathrm{m}$ & $\mathrm{D}_{1}$ & $\mathrm{D}_{2}$ & $\mathrm{D}_{3}$ & $\mathrm{D}_{4}$ & $\mathrm{D}_{5}$ \\
\hline AISI 1010 & 175 & 380 & 0.32 & 0.06 & 0.55 & -2.2 & 5.43 & -0.47 & 0.016 & 0.63 \\
\hline AISI 321 & 280 & 1215 & 0.43 & 0.031 & 1.15 & 0 & 1.15 & -0.1 & -0.015 & -0.5 \\
\hline
\end{tabular}

For a water jet, the NULL material model [5] is used, which is widely used to specify liquids and allows dynamic viscosity to be taken into account.

Selected material models need equations of state. The Linear Polynomial equation is used for the Johnson-Cook material model, and the Murnaghan equation is used for the NULL material model.

A contact type ERODING_NODES_TO_SURFACE is set between the workpiece and the waterjet [5].

The influence of traverserate on the depth of cut was investigated. The influence of the following traverserate values was considered: $100 \mathrm{~mm} / \mathrm{min} ; 200 \mathrm{~mm} / \mathrm{min} ; 300 \mathrm{~mm} / \mathrm{min}$; $400 \mathrm{~mm} / \mathrm{min}$. The stress distribution is obtained in the longitudinal section of the workpiece for jet velocities of $400 \mathrm{~m} / \mathrm{s}, 500 \mathrm{~m} / \mathrm{s}, 600 \mathrm{~m} / \mathrm{s}$ and $700 \mathrm{~m} / \mathrm{s}$ for carbon steel AISI 1010 (Fig. 3) and for stainless steel AISI 321 (Fig. 4). 


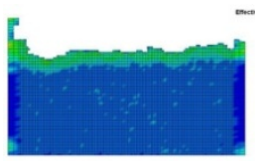

$100 \mathrm{~mm} / \mathrm{min}$

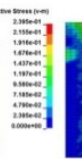

$200 \mathrm{~mm} / \mathrm{min}$

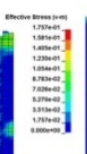

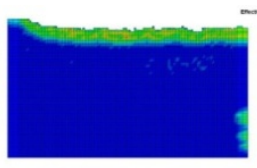

$300 \mathrm{~mm} / \mathrm{min}$

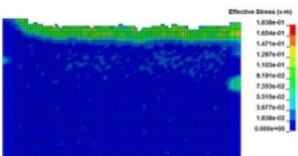

$400 \mathrm{~mm} / \mathrm{min}$

a) jet velocity $400 \mathrm{~m} / \mathrm{s}$

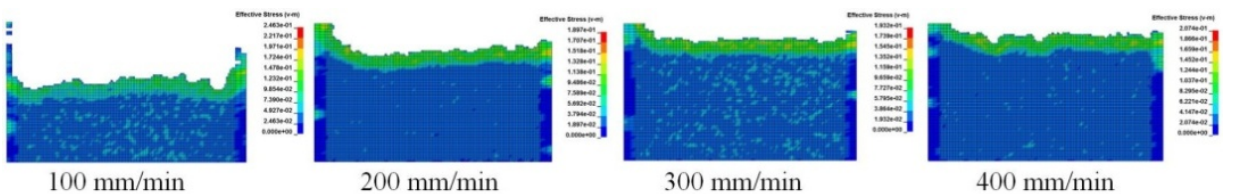

b) jet velocity $500 \mathrm{~m} / \mathrm{s}$

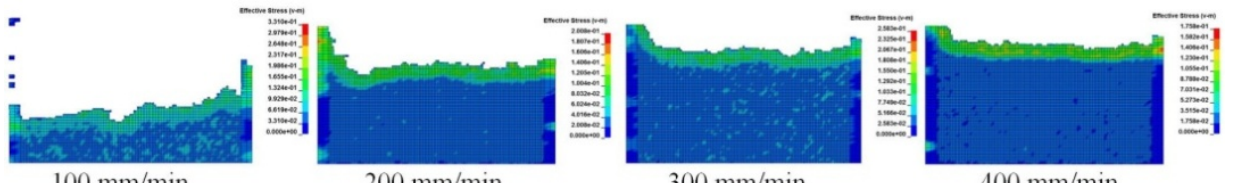

c) jet velocity $600 \mathrm{~m} / \mathrm{s}$

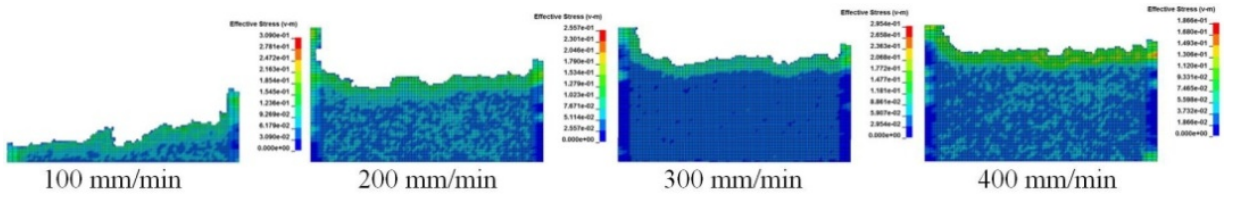

d) jet velocity $700 \mathrm{~m} / \mathrm{s}$

Fig. 3. Stress distribution for carbon steel AISI 1010 at various traverse rates

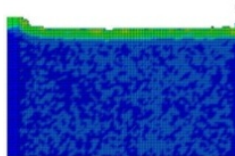

$100 \mathrm{~mm} / \mathrm{min}$

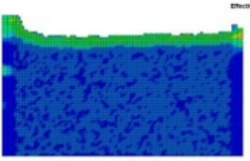

$100 \mathrm{~mm} / \mathrm{min}$
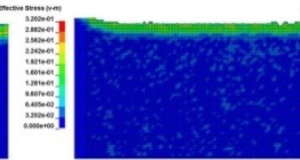

$200 \mathrm{~mm} / \mathrm{min}$

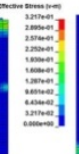

a) jet velocity $400 \mathrm{~m} / \mathrm{s}$

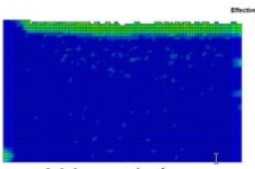

$300 \mathrm{~mm} / \mathrm{min}$


$400 \mathrm{~mm} / \mathrm{min}$

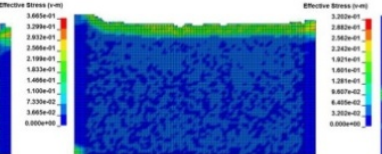

$200 \mathrm{~mm} / \mathrm{min}$

b) jet velocity $500 \mathrm{~m} / \mathrm{s}$

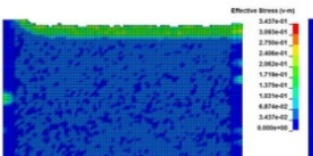

$300 \mathrm{~mm} / \mathrm{min}$

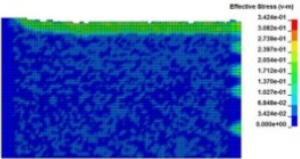

$400 \mathrm{~mm} / \mathrm{min}$



$100 \mathrm{~mm} / \mathrm{min}$
$200 \mathrm{~mm} / \mathrm{min}$

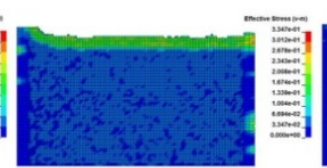

$300 \mathrm{~mm} / \mathrm{min}$

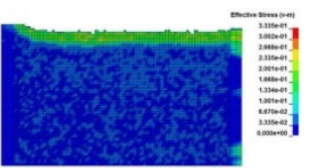

$400 \mathrm{~mm} / \mathrm{min}$

c) jet velocity $600 \mathrm{~m} / \mathrm{s}$

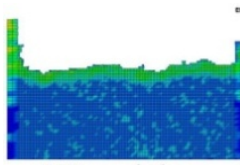

$100 \mathrm{~mm} / \mathrm{min}$

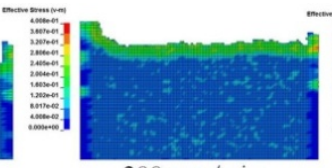

$200 \mathrm{~mm} / \mathrm{min}$

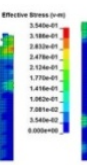

d) jet velocity $700 \mathrm{~m} / \mathrm{s}$

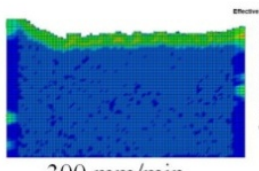

$300 \mathrm{~mm} / \mathrm{min}$
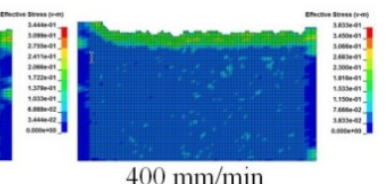

$400 \mathrm{~mm} / \mathrm{min}$

Fig. 4. Stress distribution for stainless steel AISI 321 at various traverse rates 
According to the simulation results, the dependences of the depth of cut on the traverserate for various jet velocities (Fig. 11) and the cutting force on the of the jet velocityfor various jettraverse rate (Fig. 12)are obtained during the machining of carbon and stainless steels.

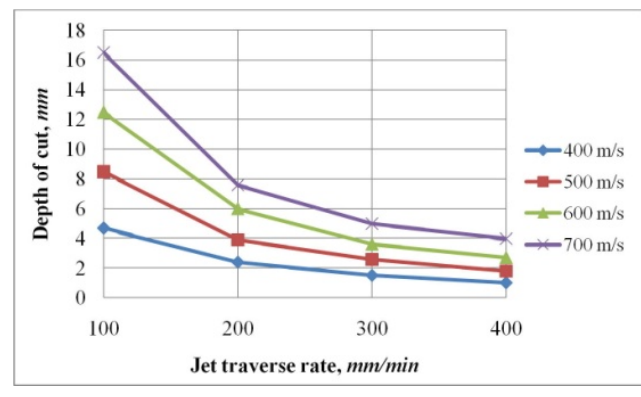

a) carbon steel AISI 1010

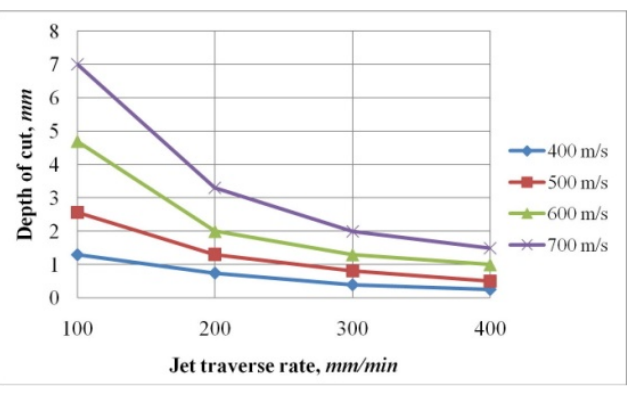

b) stainless steel AISI 321

Fig. 5. Dependences of depth of cut on jet traverse rate at various jet velocities



a) carbon steel AISI 1010

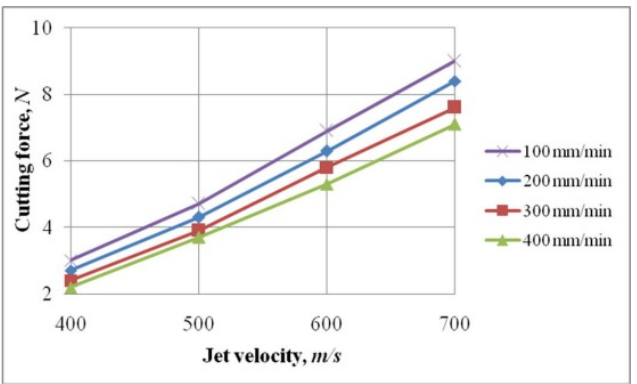

b) stainless steel AISI 321

Fig. 6. Dependences of cutting force on jet velocity at various jet traverse rates

Thisstudy allowschoosing the modes of abrasive waterjet cutting of carbon steel AISI 1010 and stainless steel AISI 321depending on workpiece thickness.

\section{References}

1. Z. Ziwei, M. Guoying, W. Aiming, Numerical Simulation of Scale Removal from Mine Drainage Pipe by Water Jet, Journal of Applied Science and Engineering, v. 21, No. 2,pp. 145-154, (2018)

2. W.Gong, J.Wang, N. Gao, Numerical simulation for abrasive water jet machining based on ALE algorithm, Springer-Verlag London Limited, v.53,pp. 247-253,(2011)

3. J.Liu, M.Wang, D.Zhang,Numerical Simulation of High Pressure Water Jet Impacting Concrete,AIP Conf. Proc.,v.1864, pp. 1-6, (2017)

4. M. Kyriaki, K. Thomas, B. Nicholaos, A. Aristomenis, A finite element-based model for pure waterjet process simulation, Springer-Verlag London Limited, v.31,pp. 933940, (2006)

5. J. Wang, N. Gao, W. Gong, Abrasive waterjet machining simulation by SPH method, Springer-Verlag London Limited, v. 50, pp. 227-234, (2010) 